\title{
An Overview of Research Methodology in Information System (IS)
}

\author{
Mohamed Al Kilani, Volodymyr Kobziev \\ Kharkov National University of Radio Electronics, Kharkov, Ukraine \\ Email: moh_alkilani@yahoo.com,vgkobzev55@gmail.com
}

How to cite this paper: Al Kilani, M. and Kobziev, V. (2016) An Overview of Research Methodology in Information System (IS). Open Access Library Journal, 3: e3126. http://dx.doi.org/10.4236/oalib.1103126

Received: October 9, 2016

Accepted: November 4, 2016

Published: November 4, 2016

Copyright $\odot 2016$ by authors and Open Access Library Inc.

This work is licensed under the Creative Commons Attribution International License (CC BY 4.0).

http://creativecommons.org/licenses/by/4.0/

\begin{abstract}
Research methodology in a research study is considered as an important element, and therefore determining the method of research methodology is a very important section in the study. Research methodology is useful to establish the structure of research, such as strategy, approach, research philosophy, and components of the methodology. This paper aims to give and clarify the components of research methodology in Information System (IS), and highlight the differences between qualitative approach and quantitative approach, as well as justification for use of the case study in Information System (IS).
\end{abstract}

\section{Subject Areas}

Computer Engineering

\section{Keywords}

Qualitative, Quantitative, Case Study, Data Collection, Validity, Reliability

\section{Introduction}

Research methodology in the area of Information Systems (IS) can be categorized under different subjects and encompasses many areas, such as: Technology, Management, Political Science and Strategy. Research methodology is one of the important tools in research studies to identify the problems which need to be investigated, and reach the set objectives in a research study [1]. It can be described as a method for collecting data and analysis; these methods have to be compatible with research problems to get accurate and realistic result [2].

Research methodology can be classified in different ways, the most common and widely used are the qualitative approach and the quantitative approach [3]. The re- 
search methodology clarifies and delineates the study aims and identifies the requirements to fit the research needs [4]. Iacono, Brown and Holtham (2009) [5] noted that research methodology referred to how to use the techniques and procedures in the research design. It can be used to distinguish between methods and results. Research methodology is partial important to achieve and clarify the main key of research aims. The main purpose of research methodology is to give a clear idea on what methods or process are going to use, as well as discuss the research problems in order to be addressed. Therefore, the research methodology is an important element to the research studies to clarify all the needed steps to achieve the objectives of the research.

This work aims to clarify the methodology that can be selected by the author to apply on the research study and give a clear picture on the most applicable methods of gathering data for the study. However, this paper includes seven sections, Section 1 is the introduction. The second section distinguishes between qualitative approach and quantitative approach. The third section explains the research strategy. The fourth section discusses data collection. The fifth section illustrates validity and reliability. The sixth section is about research design, and the last section will be the conclusion.

The objectives of this research are:

- To give an overview of research methodology and its importance in the research studies.

- To define quantitative and qualitative research methodologies and compare the strengths and weaknesses.

- To give an overview of research strategy and identify the reason of choosing case study when researching the field of information system (IS).

\section{Research Approach}

Babbie (2012) [6], identified research approach as: "systematic and orderly approach taken towards the collection and analysis of data so that information can be obtained from those data". It is very important to understand the aims of research clearly to determine and choose the appropriate technique to achieve research's aims [7].

During selecting research approach there are two factors must be considered, which are the characteristics of the topic and time to conduct the research; and statement that there three approaches to research (quantitative approach, qualitative approach, and mixed-method approach [8].

However, the selection of appropriate research for Information Systems (IS) is not easy task, because IS enables researchers to choose a suitable method from different research approaches, as well as take into account the aims of research to be achieved.

The next section explains the main characteristics of the two methods and constructs a comparison between them

\subsection{Qualitative Approach}

The qualitative research approach often depends on the interpretive or critical paradigm within social sciences to help researchers to study social and cultural phenomena; it is the approach that represents collect data depends on the field or life situation such 
as experiences, values, and behaviors of other people [9]. On the other hand (Jebreen, 2012; Wright and Losekoot, 2010; Zakaria, 2004) [7] [10] [11], defined that the data in qualitative research come in form as words, phrases, sentences and narrations rather than numbers (non-numerical data) e.g. explanation, conversation, interviews and discussion, which makes the collected data of qualitative rich and holistic with strong potential for revealing complexity, through focusing on problems in their social and cultural environments.

The qualitative approach method provides explanations to explore a particular phenomenon, theory building and capturing everyday life through data collection and analysis, which shifts the philosophical assumptions to appropriate research design and technique data [12] [13] .

\subsection{Quantitative Approach}

The quantitative approach includes the interpretation of numeric data such as percentages, interval or ratio and using items of analysis such as graphs or diagrams to get perfect results [9] [14]. The quantitative approach can be described as an extreme of empiricism, which depends on control and explanation of the phenomenon. The quantitative researchers are more interested to measure about "how many?", "how often?", or "to what extent?" [11].

Quantitative research in the analysis of data depends on statistical principles, and this contrary to qualitative research, which is preferred when there is little researches into the phenomenon needs to be investigated to be more understood. Table 1 outlines a summary of the strength and weaknesses of qualitative research method and quantitative research method.

In qualitative and quantitative approaches there are different methods of concept; Table 2 outlines the comparison between the two methods in terms of concepts, processes, and analysis.

Table 1. Strengths and weaknesses of the qualitative and quantitative methods.

\begin{tabular}{|c|c|c|}
\hline $\mathrm{Me}$ & Strength & Weaknesses \\
\hline Qua & $\begin{array}{l}\text { - The qualitative analysis allows a complete, rich and detailed description. } \\
\text { - Can be faster when compared to quantitative methods. } \\
\text { - Does not reduce complex human experiences to numerical form } \\
\text { and allows a good insight into a person's experiences and behavior. } \\
\text { - Qualitative methods can be cheaper than quantitative research. } \\
\text { - Ambiguities, which are inherent in human language, can be } \\
\text { recognized in the analysis. }\end{array}$ & $\begin{array}{l}\text { - Qualitative data is difficult to analyze and } \\
\text { needs a high level of interpretative skills. } \\
\text { - Good chance of bias. } \\
\text { - } \text { - Quard to draw brief conclusions from } \\
\text { - Lualitative data. }\end{array}$ \\
\hline
\end{tabular}

(Source: Bernard, 2000) [15] 
Table 2. Comparison of quantitative and qualitative methodologies.

\begin{tabular}{lll}
\hline \multicolumn{1}{c}{ Qualitative } & \multicolumn{1}{c}{ Quantitative } \\
\hline $\begin{array}{l}\text { 1. It is often an inductive process and the language is informal. } \\
\text { 2. Can be faster and cheaper compared with quantitative. }\end{array}$ & 1. It is a deductive process and the language is formal. \\
3. Concepts are in the form of themes, motifs, and taxonomies. & 3. Concepts are in the form of distinct variables. \\
4. The analysis proceeds by extracting themes or generalizations & 4. The analysis proceeds by using statistics, tables, or charts. \\
from evidence and organizing data to present a coherent picture. & 5. Procedures are standard and replication is assumed. \\
\hline
\end{tabular}

(Source: Bernard, 2000).

\section{Research Strategy}

Sunder et al. [16], defined research strategy as "the general plan of how the researcher will go about answering the research questions". Research strategy, according to Weduawatta et al. [1], "provides the overall direction of the research including the process by which the research is conducted". Rowley [17] argues that a chosen of research strategy depending on research questions as well as goals of the research.

Weduawatta et al. [1] mentioned that research strategy selected based on three conditions, which are:

The type of question

The control the researcher has over behavioral events

The focus on contemporary as opposed to historical events

Research strategy can be defined as develop a clear plan to research and clarify research's aims, to enabling the researcher to conduct research systematically rather than haphazardly.

\section{Case Study}

Yin [18], defined case study as-"A case study is an empirical inquiry that investigates a contemporary phenomenon within its real-life context, especially when the boundaries between phenomenon and context are not clearly evident". Zakaria [11] noted that 'how' and 'why' questions are frequently posed, case studies are the preferred strategy.

In research strategy, the case study is most common when the phenomenon cannot be divorced from its context, which depends on qualitative approach as a method to be used in an information system [1] [5].

The case study considers as method that can investigation a contemporary phenomena when there is a lack of knowledge and context of phenomena are not clearly [17] [16].

Onatu [19], state that there three reasons to choose case study when research in field of information system (IS):

- Case study enables the researcher to study information system (IS) in its natural settings, and generate theories from practice.

- Case study enables the researcher to answer "how" and "why" questions, to gain more explicit information. 
- Case study enables the researcher to the nature and complexity of the process taking place.

\section{Single-Multiple Case Studies}

Case studies can be classified into a single case or multiple cases; a single case provides all needed information about research question from one organization. In a single case, information and data from one unit is enough to achieve the aims of the research. Multiple case studies require data from more one unite to achieve research objectives. Sunders et al. [20] defined a single case as "A single case is often used where it represents a critical case or, alternatively, an extreme or unique case", also noted that multiple cases used more than one case to compare whether the findings of the first case occur in other cases. Yin [18], claims that single case is more relevant if:

1. It is a revelatory case.

2. It represents a critical case for testing a formulated theory.

3. It is a unique case.

On the other hand Baxter and Susan [21], state that multiple cases enable the researchers to study and compare the findings between different cases, and thus explore differences within and between cases; which enable the researchers to forecast the results.

\section{Data Collection Method}

Data collection in the case study is one of the most important methods, this method is the most effective method to collect data and uncover all the details relevant to the research. The data collection and analysis can contribute to support research propositions, and pointed out that there are three protocols, that include the following [17]:

1. An overview of the case study project.

2. Field procedures, such as a use of different sources of information, and access arrangements to these sources.

3. Case study questions, or the questions that the case study researcher needs to keep in mind when collecting data.

The researchers pointed out that there are different sources to collecting data, which are: Interview; Documents; Direct observations [5] [22] [23] [24]. While, Yin [18], has identified six methods of data collection for the case study, these six sources are: Documentation, Archival records, Focus group interviews, Direct observation, Participant observation, Physical Artifacts.

The most method of data collection is:

\subsection{Interviews}

The interview has the ability to clarify all issues incomplete or unclear, by asking additional questions, this method enable the researcher to understand interviewee clearly as well their point of view, the interview has flexibility and adapts the situations to each subject. The interviewer has to ensure that the interviewees were informed about the purpose of the interviews [25]. 
Yin [26], state that "one of the most important sources of case study information is the interview". He suggested other names for interview forms, namely: open-ended, focused, and structured (survey) interviews. Open-ended interviews are two-way open communications; enable researchers to ask respondents for the facts as well their opinions. Focused (semi-structured) interviews aim to purpose the research questions in a purposeful way. While, structured interviews, research questions more structured. The semi-structured interview has flexibility more than other types of interviews, and it has the ability to extract more detailed data from the participants and get fresh commentaries and significant insights. Also, it is the useful method to access individuals to get their opinions, which cannot secure by formal questionnaire or open-ended interviews, flexible questions have a better response than closed questions [11]. The semi-structured interviews as "a discussion between two or more individuals in which a set of questions are posed" [20].

\subsection{Documentation}

Documentation is an important tool to most schemes and social research, because of its location in the historical circumstances; as well it has the possibility of reviewing repeatedly. The document is a way of collecting data, and it can be an essential source of any investigation, and alternative method of collecting information rather than questionnaire survey, interview and observations [11].

There are three reasons make the documents one of the useful methods of data collection. "First, it used as inputs to the interview guide and saved time Second, useful for tracing the history of the organizations and statements.Third, helpful in counteracting the biases of the interviews", [24]. Documents are provided the possibility to supplement needed information from other resources and highlight the new ideas and insights that need further investigation by a researcher [26].

\subsection{Questionnaire}

The questionnaire is a research instrument contains a set of questions and prompts and allows the researcher for gathering information from respondents. The questionnaire is one of the widely used methods of data collection, in initially it was designed for the purpose of statistical analysis, and the main advantage of the questionnaire is the flexibility of collecting data, therefore now it is being used in other types of statistical analysis.

Nicholas [27], pointed out that questionnaire is flexible tool enable the researchers to organize the questions and receive replies from respondents without needed to talk with each one separately.

The questionnaire helpful but must take into account set of points:

- Careful design of questions.

- The questionnaire must be easy to understand and uncomplicated.

- Clarify the purpose of the questionnaire.

- Language and terminology. 


\section{Validity and Reliability}

The basic goals of the design of questionnaire are, firstly obtain information relevant to a research study, secondly to collect data within maximum reliability and validity. Some researchers pointed out according to the field of Information Systems (IS), validity and reliability must be achieved in all research studies. In qualitative studies there are different method can use to address both of validity and reliability, and include "triangulation of information among different sources of data, receiving feedback from informants (member checking), and expert review" [28]. On the other hand Meyer [24], argue that the most qualitative researchers in their studies focus on the findings rather than explain or describe how these results were collected. The validity and reliability can be achieved when there is a clear explanation of the techniques used to collect needed data, and enabling the interviewee to assemble documentation that can support interview. He also added that the validity and reliability can be increased depending on: careful design of individual questions; clear and pleasing layout of the questionnaire; lucid explanation of the purpose of the questionnaire; pilot testing; carefully planned and executed administration [20] [28].

\section{Research Design}

Research design aims to give a clear picture of the structure of the research and the used methods such as data collection, research questions, and sources of data. Research design enables the researcher outline all needed method and tools for the research like selecting theory of project and research methodology.

The research design is a method of inquiry within different approaches to research such as qualitative, quantitative, and mixed methods, and a diagram or a figure can be used to illustrate the structure of research [8]. The research design is an action plan to move from stage of methodology to the next stage. However, drawing units of research is very helpful to arrange the collected data in the right format, also provides a map to understand the research and useful to other researchers to follow [26].

\section{Conclusions}

There are different methods of research methodologies which have been explored by researchers in the field of Information System (IS), each method has its assumptions and approach in data collection and has been processed to achieve the objectives of the research. Research methodology centers on how to choose the appropriate method for data collection and analysis. On the other hand, research methodology can be defined as a strategy to focus on researching problems and developing appropriate solutions.

This paper aims to give an overview of research method in an information system, identify all needed elements of data collection in the research study, and discuss the differences between qualitative approach and quantitative approach, as well as strengths and weaknesses for both types. 


\section{References}

[1] Wedawatta, G., Ingirige, B. and Amaratunga, D. (2011) Case Study as a Research Strategy: Investigating Extreme Weather Resilience of Construction SMEs in the UK. 7th Annual International Conference of International Institute for Infrastructure, Kandalama, July 2011, 1-9.

[2] Harling, K. (2002) An Overview of Case Study. Agricultural Economics, 4, 1-7.

[3] Alrawabdeh, W. (2014) The Impact of Environmental Factors on E-Government Implementation: The Case of Jordan. International Journal of Management Sciences and Business Research, 3, 1-7.

[4] Ziemba, E., Papaj, T. and Żelazny, R. (2013) A Model of Success Factors for E-Government Adoption-The Case of Poland. Issues in Information Systems, 14, 87-100.

[5] Iacono, J., Brown, A. and Holtham, C. (2009) Research Methods-A Case Example of Participant Observation. The Electronic Journal of Business Research Methods, 7, 39-46.

[6] Babbie, E. (2012) The Practice of Social Research. 13th Edition.

[7] Wright, N. and Losekoot, E. (2012) Interpretative Research Paradigms: Points of Difference. Proceedings of the 11 th European Conference on Research Methods in Business Management: ECRM2012, 416-422.

[8] Creswell, J.W. (2003) Research Design Qualitative Quantitative and Mixed Methods Approaches. Sage, Thousand Oaks, 3-26.

[9] Choy, L.T. (2014) The Strengths and Weaknesses of Research Methodology: Comparison and Complimentary between Qualitative and Quantitative Approaches. Journal of Humanities and Social Science, 19, 99-104.

[10] Jebreen, I. (2012) Using Inductive Approach as Research Strategy in Requirements Engineering. International Journal of Computer and Information Technology, 1, 162-173.

[11] Zakaria, O. (2004) Understanding Challenges of Information Security Culture: A Methodological Issue. Proceedings of the 2nd Australian Information Security Management Conference, Perth, 26 November 2004, 83-93.

[12] Zachariadis, M., Scott, S. and Barrett, M. (2013) For Mixed methods Research. Management Information Systems Quarterly, 37, 855-879.

[13] Andrade, A.D. (2009) Interpretive Research Aiming at Theory Building: Adopting and Adapting the Case Study Design. The Qualitative Report, 14, 42-60.

[14] Thorne, S., Kirkham, S.R. and O’Flynn-Magee, K. (2004) The Analytic Challenge in Interpretive Description. International Journal of Qualitative Methods, 3, 1-11.

[15] Bernard, H. (2000) Social Research Methods: Qualitative and Quantitative Approaches, Sage, Thousand Oaks.

[16] Zaidah, Z. (2007) Case Study as a Research Method. Jurnal Kemanusiaan, 9, 1-6.

[17] Rowley, J. (2002) Using Case Studies in Research. Management Research News, 25, 16-27. http://dx.doi.org/10.1108/01409170210782990

[18] Yin, R. (2009) Case Study Research: Design and Methods. 4th Edition, Sage, Thousand Oaks.

[19] Onatu, G.O. (2013) Building Theory from Case Study Research : The Unanwered Question in Social Sciences. 1 st Global Virtual Conference, 1, 170-173.

[20] Saunders, M., Lewis, P. and Thornhill, A. (2009) Research Methods for Business Students. Pearson, New York.

[21] Baxter, P. and Jack, S. (2008) Qualitative Case Study Methodology: Study Design and Im- 
plementation for Novice Researchers. The Qualitative Report, 13, 544-559.

[22] Njie, B. and Asimiran, S. (2014) Case Study as a Choice in Qualitative Methodology. IOSR Journal of Research \& Method in Education, 4, 35-40. http://dx.doi.org/10.9790/7388-04313540

[23] Sharma, G., Bao, X. and Peng, L. (2014) Public Participation and Ethical Issues on E-Governance : A Study Perspective in Nepal. Electronic Journal of E-Government, 12, 82-96.

[24] Meyer, C. (2001) A Case in Case Study Methodology. Field Methods, 13, 329-352. http://dx.doi.org/10.1177/1525822X0101300402

[25] Al-Azri, A., et al. (2010) The Successful Implementation of E-Government Transformation: A Case Study in Oman. European, Mediterranean \& Middle Eastern Conference on Information Systems, Abu Dhabi, 12-13 April 2010, 1-11.

[26] Yin, R. (2003) Case Study Research: Design and Methods. 3rd Edition, Sage, Thousand Oaks.

[27] Walliman, N. (2001) Your Research Project: A Step by Step Guide for the First Time Researcher. Sage, Thousand Oaks.

[28] Simon, M. (2011) Validity and Reliability in Qualitative Research. Curationis, 16, 35-38.

\section{Submit or recommend next manuscript to OALib Journal and we will provide best} service for you:

- Publication frequency: Monthly

- 9 subject areas of science, technology and medicine

- Fair and rigorous peer-review system

- Fast publication process

- Article promotion in various social networking sites (LinkedIn, Facebook, Twitter, etc.)

- Maximum dissemination of your research work

Submit Your Paper Online: Click Here to Submit

Or Contact service@oalib.com 